NASA/TM-2005-213560

\title{
Thermal Evaluation of Fiber Bragg Gratings at Extreme Temperatures
}

Jeffrey Juergens and Grigory Adamovsky

Glenn Research Center, Cleveland, Ohio

Ramakrishna Bhatt

U.S. Army Research Laboratory, Glenn Research Center, Cleveland, Ohio

Gregory Morscher

Ohio Aerospace Institute, Brook Park, Ohio

Bertram Floyd

Akima Corporation, Fairview Park, Ohio 
Since its founding, NASA has been dedicated to the advancement of aeronautics and space science. The NASA Scientific and Technical Information (STI) Program Office plays a key part in helping NASA maintain this important role.

The NASA STI Program Office is operated by Langley Research Center, the Lead Center for NASA's scientific and technical information. The NASA STI Program Office provides access to the NASA STI Database, the largest collection of aeronautical and space science STI in the world. The Program Office is also NASA's institutional mechanism for disseminating the results of its research and development activities. These results are published by NASA in the NASA STI Report Series, which includes the following report types:

- TECHNICAL PUBLICATION. Reports of completed research or a major significant phase of research that present the results of NASA programs and include extensive data or theoretical analysis. Includes compilations of significant scientific and technical data and information deemed to be of continuing reference value. NASA's counterpart of peerreviewed formal professional papers but has less stringent limitations on manuscript length and extent of graphic presentations.

- TECHNICAL MEMORANDUM. Scientific and technical findings that are preliminary or of specialized interest, e.g., quick release reports, working papers, and bibliographies that contain minimal annotation. Does not contain extensive analysis.

- CONTRACTOR REPORT. Scientific and technical findings by NASA-sponsored contractors and grantees.
- CONFERENCE PUBLICATION. Collected papers from scientific and technical conferences, symposia, seminars, or other meetings sponsored or cosponsored by NASA.

- SPECIAL PUBLICATION. Scientific, technical, or historical information from NASA programs, projects, and missions, often concerned with subjects having substantial public interest.

- TECHNICAL TRANSLATION. Englishlanguage translations of foreign scientific and technical material pertinent to NASA's mission.

Specialized services that complement the STI Program Office's diverse offerings include creating custom thesauri, building customized databases, organizing and publishing research results ... even providing videos.

For more information about the NASA STI Program Office, see the following:

- Access the NASA STI Program Home Page at http://www.sti.nasa.gov

- E-mail your question via the Internet to help@sti.nasa.gov

- Fax your question to the NASA Access Help Desk at 301-621-0134

- Telephone the NASA Access Help Desk at 301-621-0390

- Write to:

NASA Access Help Desk

NASA Center for AeroSpace Information 7121 Standard Drive

Hanover, MD 21076 
NASA/TM-2005-213560

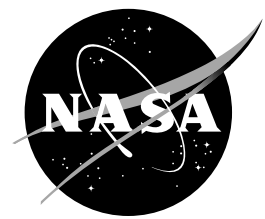

\section{Thermal Evaluation of Fiber Bragg Gratings at Extreme Temperatures}

Jeffrey Juergens and Grigory Adamovsky

Glenn Research Center, Cleveland, Ohio

Ramakrishna Bhatt

U.S. Army Research Laboratory, Glenn Research Center, Cleveland, Ohio

Gregory Morscher

Ohio Aerospace Institute, Brook Park, Ohio

Bertram Floyd

Akima Corporation, Fairview Park, Ohio

Prepared for the

43rd Aerospace Sciences Meeting and Exhibit

sponsored by the American Institute of Aeronautics and Astronautics

Reno, Nevada, January 10-13, 2005

National Aeronautics and

Space Administration

Glenn Research Center 


\section{Acknowledgments}

This work was sponsored by the Alternate Fuel Foundation Technologies Subproject of the Low Emissions Alternative Power Project at the NASA Glenn Research Center. The authors would like to thank Eric Udd, Caryn Mayor, and Dan Miller, from Blue Road Research, for helping to identify the manufacturer of the FBGs used in this work. Finally the authors would also like to acknowledge the help of Bernard Malo and Francois Bilodeau for providing the manufacturing specifications of the FBGs used in this work.

This report is a formal draft or working paper, intended to solicit comments and ideas from a technical peer group.

contains preliminary

findings, subject to revision as analysis proceeds.

Trade names or manufacturers' names are used in this report for identification only. This usage does not constitute an official endorsement, either expressed or implied, by the National Aeronautics and Space Administration.

This work was sponsored by the Low Emissions Alternative

Power Project of the Vehicle Systems Program at the NASA Glenn Research Center.

Available from

NASA Center for Aerospace Information 7121 Standard Drive

Hanover, MD 21076
National Technical Information Service 5285 Port Royal Road Springfield, VA 22100 


\title{
Thermal Evaluation of Fiber Bragg Gratings at Extreme Temperatures
}

\author{
Jeffrey Juergens and Grigory Adamovsky \\ National Aeronautics and Space Administration \\ Glenn Research Center \\ Cleveland, Ohio 44135 \\ Ramakrishna Bhatt \\ U.S. Army Research Laboratory \\ Glenn Research Center \\ Cleveland, Ohio 44135 \\ Gregory Morscher \\ Ohio Aerospace Institute \\ Brook Park, Ohio 44142 \\ Bertram Floyd \\ AKIMA Corporation \\ Fairview Park, Ohio 44126
}

\begin{abstract}
The development of integrated fiber optic sensors for use in aerospace health monitoring systems demands that the sensors be able to perform in extreme environments. In order to use fiber optic sensors effectively in an extreme environment one must have a thorough understanding of the sensor's capabilities, limitations, and performance under extreme environmental conditions. This paper reports on our current sensor evaluation examining the performance of freestanding fiber Bragg gratings (FBG) at extreme temperatures. While the ability of FBGs to survive at extreme temperatures has been established, their performance and long term survivability is not well documented. At extreme temperatures the grating structure would be expected to dissipate, degrading the sensors performance and eventually ceasing to return a detectable signal. The fiber jacket will dissipate leaving a brittle, unprotected fiber. For FBGs to be used in aerospace systems their performance and limitations need to be thoroughly understood at extreme temperatures. As the limits of the FBGs performance are pushed the long term survivability and performance of the sensor comes into question. We will not only examine the ability of FBGs to survive extreme temperatures but also look at their performance during many thermal cycles. This paper reports on test results of the performance of thermal cycling commercially available FBGs, at temperatures up to $1000^{\circ} \mathrm{C}$, seen in aerospace applications. Additionally, this paper will report on the performance of commercially available FBGs held at $1000^{\circ} \mathrm{C}$ for hundreds of hours. Various parameters of the FBGs performance were monitored and recorded throughout the evaluation process. Several test samples were subjected to identical test conditions to allow for statistical analysis of the data. Test procedures, calibrations, referencing techniques, performance data, and interpretations and explanations of results are presented in the paper along with directions for future research.
\end{abstract}

\section{INTRODUCTION}

With the growing interest to use FBGs as temperature sensors in aerospace systems, the need to understand the performance and long term survivability of commercially available high temperature $\mathrm{FBGs}$, up to $1000^{\circ} \mathrm{C}$, has developed $[1,2,3]$. The survivability of FBGs up to and above $1000^{\circ} \mathrm{C}$ has generated interest $[4,5]$, but their per- 
formance and long term survivability at these temperatures is not well published. This paper looks at, in great detail, the performance and long term survivability of FBGs up to $1000^{\circ} \mathrm{C}$ through more than 700 hours of thermal cycling and over 400 hours of continuous operation.

FBGs in standard telecommunications fiber were used throughout the evaluation. They were fabricated for use up to $400^{\circ} \mathrm{C}$ so it was expected that the FBG structure would completely dissipate. However, this was not what was observed. Degradation and loss of the signal from the FBGs was observed during the beginning of the evaluation but the signal eventually reappeared and stabilized. The results of the experiments are discussed below along with theories for the phenomena observed during the evaluation.

Additional experiments were preformed to explain phenomenon seen during the optical portion of the thermal analysis. Sections of fiber were monitored for cracking using an acoustic emissions technique. Results of those experiments are also discussed.

\section{HIGH TEMPERATURE THERMAL CYCLING OF FBGS}

All FBGs were commercially available and of a like construction and were evaluated to look at their suitability for use in aerospace applications. All had a polyimide jacket designed to withstand high temperature operation up to $400^{\circ} \mathrm{C}$. High reflectivity, type I, gratings made using a Spectran fiber similar to Corning SMF28 were evaluated. They had a core diameter of 9 micron, a germanium doped core, and were hydrogen loaded. The gratings were produced with a $193 \mathrm{~nm}$ Excimer laser. Prior to our evaluation the gratings were annealed to $400^{\circ} \mathrm{C}$ for about five minutes by the manufacturer. [6]

Evaluation of the FBGs consisted of four experiments all performed in ambient air; cycling to $750^{\circ} \mathrm{C}$; cycling to $1000^{\circ} \mathrm{C}$; long duration at $1000^{\circ} \mathrm{C}$; and finally acoustic emissions monitor of the FBG during thermal cycling. During the thermal cycling experiments the gratings were subjected to repeated cycling to characterize the accuracy of temperature measurements made and their survivability. The experiments were designed to look at the long term survivability of the commercially available FBGs and determine their effectiveness as temperature sensors up to $1000^{\circ} \mathrm{C}$. Throughout the evaluation process, performance of the reflected signal of the FBGs was recorded. The evaluation process was designed to help determine which missions, if any, FBGs might be appropriate as temperature sensors.

The test setup, as seen in Fig. 1, consisted of a thermally stabilized super-luminescent diode light source connected to a $90 / 10$ coupler. The $10 \%$ output of the coupler was connected to a photodiode used to monitor the light source stability throughout the evaluation process. The $90 \%$ output port of the coupler was connected to the first port of a 3 port fiber optic circulator. The second port of the circulator was connected to a 4 port fiber optic switch. The four output ports of the switch were connected to up to 4 FBGs inside a box furnace. The reflected signal from the FBGs traveled back through the switch and circulator to an optical spectrum analyzer. All equipment was controlled and monitored using LabVIEW.

At the start of testing it was expected that the grating would degrade with increasing temperature until no measurable signal was detected. Additionally it was expected that there would be some devitrification of the fiber contributing to the loss in signal from the FBG [7]. Due to differences in the expansion coeffi-

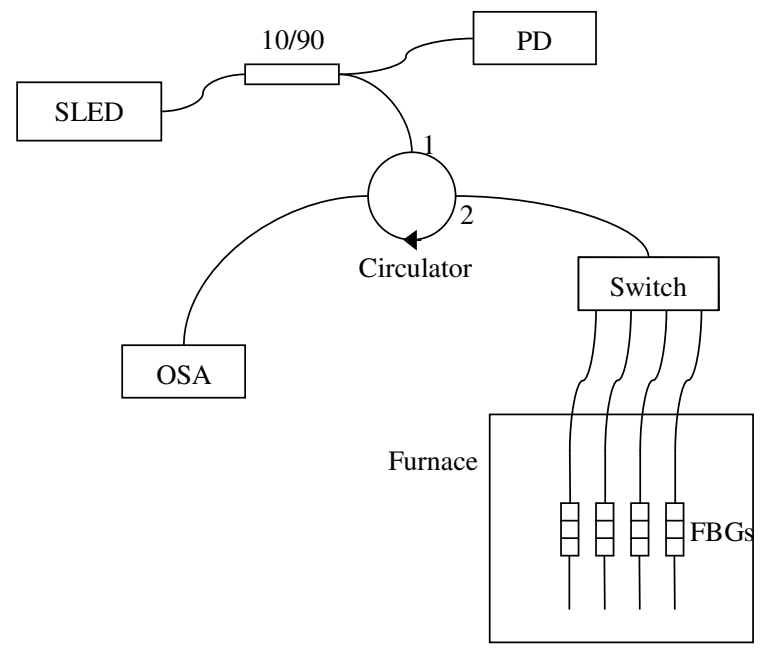

Fig. 1 Set-up for evaluating long term thermal stability of FBGs cients of the core and cladding, it was expected that there would be cracking of the fiber.

\section{A. 750 $^{\circ} \mathrm{C}$ Thermal Cycling}

The first evaluation of FBGs was a series of thermal cycles to $750{ }^{\circ} \mathrm{C}$ in ambient air. In this test, four identical $1300 \mathrm{~nm}$ FBGs were subjected to a series of slow thermal cycles designed to characterize the accuracy of temperature measurements made and their survivability. Various performance parameters of the FBGs were monitored 
throughout the test to allow for a statistical analysis of the lifetime of the FBGs under the test conditions. The temperature was also recorded using an s-type thermocouple.

The experimental configuration for the $750^{\circ} \mathrm{C}$ cycling used four identical FBGs placed in $1 / 4$ inch ID ceramic tubes inside of a box furnace. The fibers were placed in the tubes to give structural support for the fiber once the polyimide jacket evaporated. The fibers were positioned in the ceramic tubes such that there was no stress on the bare, unjacketed gratings. The experiment subjected the FBGs to 11 thermal cycles up to $750^{\circ} \mathrm{C}$ for a total of 66 hours at temperature. The thermal cycles were performed as follows: heat from ambient to $750^{\circ} \mathrm{C}$ at $1^{\circ} \mathrm{C}$ per minute; hold at $750^{\circ} \mathrm{C}$ for 6 hours; cool to $30^{\circ} \mathrm{C}$ at $1^{\circ} \mathrm{C}$ per minute.

\section{B. $7^{\circ 5}{ }^{\circ} \mathrm{C}$ Thermal Cycling Observations}

Throughout the $750^{\circ} \mathrm{C}$ evaluation, all four gratings exhibited very similar performance characteristics. All gratings had a shift of approximately $1.2 \mathrm{~nm}$ per $100^{\circ} \mathrm{C}$ in Bragg wavelength with temperature as seen in Fig. 3. The magnitude of the shift in the Bragg wavelength is typical for $1300 \mathrm{~nm}$ FBGs and while the shift was relatively linear, a $2^{\text {nd }}$ order polynomial does seem to be a better fit through the temperature range studied in this paper as the response is not exactly linear.

As expected, the initial FBG dissipated relatively quickly taking only three thermal cycles to $750^{\circ} \mathrm{C}$ to completely dissipate as can be seen in Fig. 2. On average it took a total of 92.1 hours for the original FBG to dissipate equating to an average of 14.5 hours at $750^{\circ} \mathrm{C}$. Once the original FBG had dissipated there was a period of about 40 hours in which no measurable signal was reflected from the FBG. However after approximately 40 hours of no signal, during the fourth thermal cycle, and after an average total test time of 132.1 hours, and 21.3 hours at $750^{\circ} \mathrm{C}$, a new grating formed and a signal was detected. The newly formed Bragg grating, referred to as an oxygen-chemical composition grating or O-CCG in the literature [8], exhibited a response similar to the original FBG.

The original grating structure that dissipated was the result of a photoinduced change in the optical properties of the fiber. The O-CCGs that formed during our experiment are formed through a different mechanism. They are described by Fokine as a modulation of the chemical composition in the core of an optical fiber [8]. The thermal stability of the original photoinduced gratings is likely limited by the thermal stability of the induced birefringence whereas the thermal stability of the O-CCG is "limited by the fringe-to-fringe diffusion of the modulated concentration of ... dopants [5]."

The Bragg wavelength of the original FBG and the newly formed O-CCG exhibited somewhat opposite behaviors at temperature. While at $750^{\circ} \mathrm{C}$, the original $\mathrm{FBG}$ exhibited a decrease in the Bragg wavelength of about $0.06 \mathrm{~nm}$. This initial shift to a shorter wavelength, also seen by Pal et al [2] and Brambilla [9], occurred through the

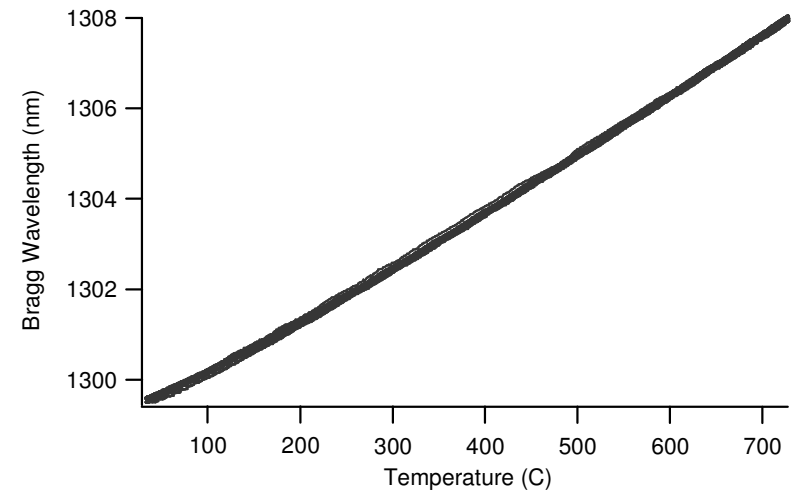

Fig. 3. Typical Bragg wavelength versus temperature response of an $\mathrm{FBG}$ during $750^{\circ} \mathrm{C}$ thermal cycling.

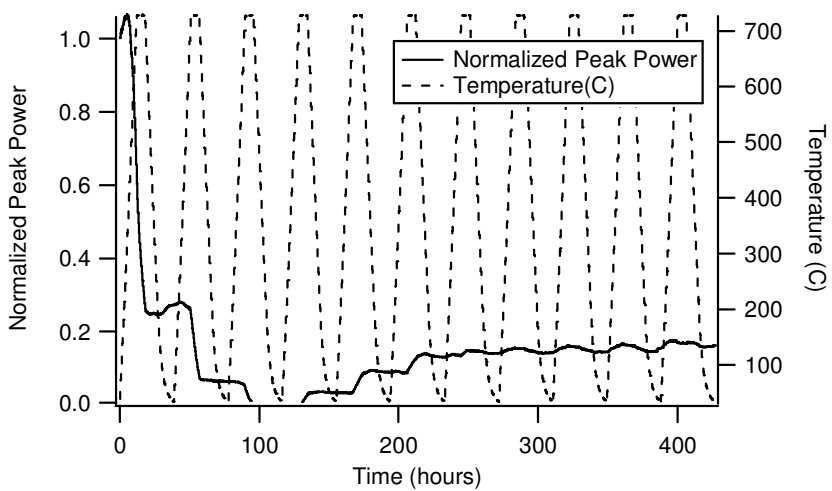

Fig. 2. Typical peak reflected power of an FBG during $750^{\circ} \mathrm{C}$ thermal cycling. The solid line is the normalized reflected power and the dashed line is the grating. The initial grating's dissipation is evident in the first 100 hours of the experiment followed by the formation of the $\mathrm{O}$ $\mathrm{CCG}$.

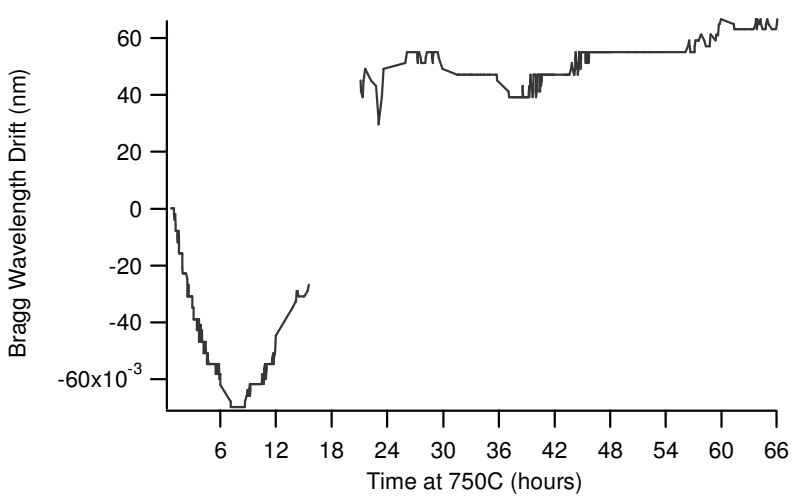

Fig. 4. Typical Bragg wavelength drift during only the $750^{\circ} \mathrm{C}$ portion of thermal cycling. The gap in the plot is when the original FBG had dissipated and the formation of the O-CCG. 
first 6 hours at $750^{\circ} \mathrm{C}$ and into the first few hours of the next thermal cycle. After about 8 hours of decrease in Bragg wavelength at $750^{\circ} \mathrm{C}$, the shift towards a shorter wavelength stopped and began to shift back to a longer wavelength. The Bragg wavelength continued to rise until the original FBG had dissipated. Once the new O-CCG formed, it exhibited far more stable Bragg wavelength characteristics at $750^{\circ} \mathrm{C}$ than the original FBG as can be seen in the last 45 hours of Fig. 4. The shift in the Bragg wavelength with temperature was still approximately $1.2 \mathrm{~nm}$ per $100^{\circ} \mathrm{C}$ but was just offset by about $0.06 \mathrm{~nm}$ at all temperatures.

With the formation of the new O-CCGs the power response began to increase as seen in Fig. 2 with the signal strength increasing each time the O-CCG was heated to $750^{\circ} \mathrm{C}$. By the end of the test the O-CCG's reflected peak power had risen to an average of $13.4 \%$ of its original strength.

With a wavelength versus temperature relationship of approximately $1.2 \mathrm{~nm}$ per $100^{\circ} \mathrm{C}$ and a drift in the Bragg wavelength of the O-CCGs of no more than $0.03 \mathrm{~nm}$ at $750^{\circ} \mathrm{C}$, the Bragg wavelength has shown to be an indicator of temperature to within $1 \%$ full scale of that measured by the reference s-type thermocouple. This is within the accuracy range of the reference temperature measurement. A complete summary of the $750^{\circ} \mathrm{C}$ thermal cycling can be seen in See Table 1.

\section{1000 $^{\circ} \mathrm{C}$ Thermal Cycling}

The second experiment performed in the evaluation of FBGs was a series of thermal cycles to $1000^{\circ} \mathrm{C}$ in ambient air. As in the $750^{\circ} \mathrm{C}$ experiment, four identical 1300nm FBGs were subjected to a series of slow thermal cycles. The four FBGs were placed in $1 / 4$ inch ID ceramic tubes inside of a box furnace. The experiment subjected the FBGs to 16 thermal cycles up to $1000^{\circ} \mathrm{C}$ for a total of 96 hours at temperature. The thermal cycles were performed in a similar manner to the $750^{\circ} \mathrm{C}$ cycling: heating from ambient to $1000^{\circ} \mathrm{C}$ at $1{ }^{\circ} \mathrm{C}$ per minute; hold at $1000^{\circ} \mathrm{C}$ for 6 hours; cool to $30^{\circ} \mathrm{C}$ at $1{ }^{\circ} \mathrm{C}$ per minute. The temperature and various parameters of the FBG's performance were recorded throughout the experiment.

\section{D. ${ }^{1000}{ }^{\circ} \mathrm{C}$ Thermal Cycling Observations}

Throughout the $1000^{\circ} \mathrm{C}$ evaluation all four gratings exhibited very similar performance characteristics. As in the $750^{\circ} \mathrm{C}$ cycling experiment, all gratings had a shift of approximately $1.2 \mathrm{~nm}$ per $100^{\circ} \mathrm{C}$ in Bragg wavelength. Similar to the $750^{\circ} \mathrm{C}$ cycling the shift in Bragg wavelength was relatively linear, however a $2^{\text {nd }}$ order polynomial would provide a much better representation of the FBG's wavelength versus temperature response.

Similar to the $750^{\circ} \mathrm{C}$ cycling, the initial FBG dissipated relatively quickly. However the dissipation of the original FBG seemed to be accelerated by the higher temperature. Before the furnace reached $1000^{\circ} \mathrm{C}$ all four gratings had dissipated. On average, the original FBG dissipated by the time the furnace had reached $870^{\circ} \mathrm{C}, 14.3$ hours into the test as seen in Fig. 5 and Fig. 8. As in the $750^{\circ} \mathrm{C}$ experiment, after the

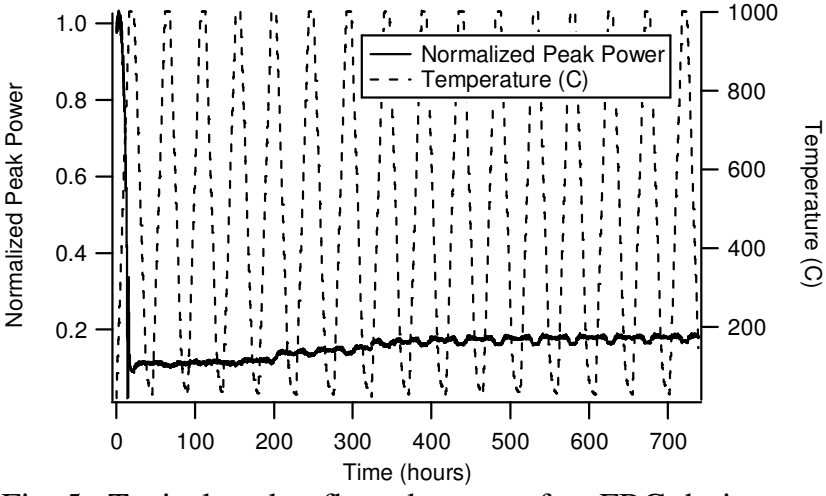

Fig. 5. Typical peak reflected power of an FBG during $1000^{\circ} \mathrm{C}$ thermal cycling. The solid line is the normalized reflected power and the dashed line is the grating temperature. As can be seen the peak power rises slightly after the O-CCG forms dropping a few percent as the FBGs are at heated.

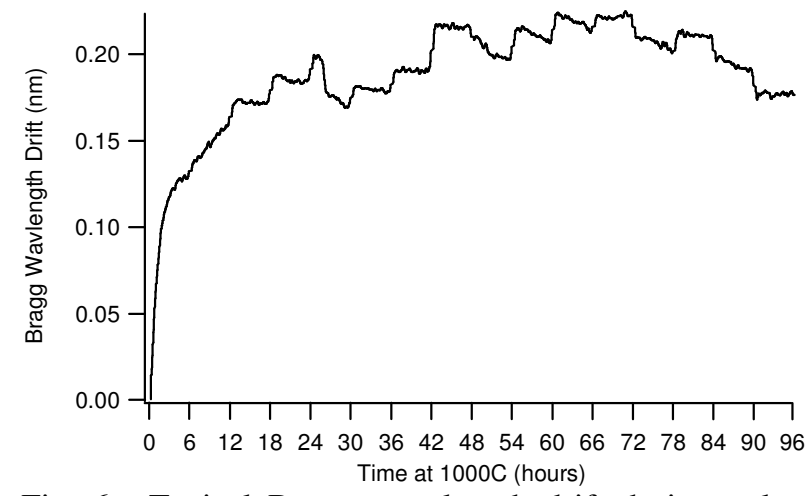

Fig. 6. Typical Bragg wavelength drift during only the $1000^{\circ} \mathrm{C}$ portion of thermal cycling. The plot shows the drift of a few tenths of a nanometer to longer wavelengths. original FBG had dissipated an O-CCG formed in place of the original grating. This new grating formed an average of 0.2 hours after the dissipation of the original FBG at an average temperature of $888^{\circ} \mathrm{C}$. The new O-CCG that formed exhibited very similar Bragg wavelength versus temperature response compared to the original FBG. However there was an initial shift in the Bragg wavelength that occurred mostly in the first six hours at $1000^{\circ} \mathrm{C}$ as seen in Fig. 6. This shift in the Bragg wavelength that was seen in the first cycle to $1000^{\circ} \mathrm{C}$ offset the temperature versus wavelength response of the gratings across the entire temperature range studied. This shift in Bragg wavelength from the first thermal cycle to the remainder of the 
cycles can easily be seen in wavelength versus temperature plot of Fig. 7. The lower line in the plot is the grating's response on the initial heating to $1000^{\circ} \mathrm{C}$. The break in the lower line is the time when the OCCG was forming and no measurable signal was reflected. The upper, broader line is the temperature response of the grating through the remainder of the thermal cycling. After this initial shift of about $0.15 \mathrm{~nm}$ to $0.20 \mathrm{~nm}$, the new $\mathrm{O}-\mathrm{CCG}$ that formed in place of the original FBG had a stable Bragg wavelength at $1000^{\circ} \mathrm{C}$ as seen in Fig. 6. There was only a few hundredths of a nanometer drift for the remainder of the experiment.

The reflected peak power response of the new $\mathrm{O}$ CCG exhibited a reversal of the degradation of the signal as seen in Fig. 5 with the reflected peak power increasing each time the new O-CCG was heated to $1000^{\circ} \mathrm{C}$. By the end of the test, the O-CCG's reflected peak power had risen to an average of $11.8 \%$ of the original signal strength, nearly twice the starting level.

Allowing for an annealing time of two thermal cycles to $1000^{\circ} \mathrm{C}$ the Bragg wavelength of the O-CCGs proved to be an accurate representation of its temperature. With a drift in the Bragg wavelength of the OCCGs of no more than $0.08 \mathrm{~nm}$ at $1000^{\circ} \mathrm{C}$ after two complete thermal cycles, the Bragg wavelength is an indicator of its temperature to within $1 \%$ full scale of that measured by the reference s-type thermocouple within the accuracy range of the reference temperature measurement. A complete summary of the $1000^{\circ} \mathrm{C}$ thermal cycling experiment can be seen in Table 1 .

\section{LONG DURATION THERMAL EVALUATION OF FBGS}

The third experiment performed in the evaluation of FBGs was a long duration evaluation at $1000^{\circ} \mathrm{C}$ in ambient air. In this experiment three identical $1550 \mathrm{~nm}$ FBGs were held at $1000^{\circ} \mathrm{C}$ for 400 hours continuous. Despite these FBGs having a different Bragg wavelength, they were fabricated in the same manner and in the same fiber as the 1300nm FBGs used in the previous experiments. As in the previous experiments, the FBGs were placed in $1 / 4$ inch ID ceramic tubes inside of a box furnace. The FBGs were heated from ambient to $1000^{\circ} \mathrm{C}$ at $1^{\circ} \mathrm{C}$ per minute, the same in the previous experiments. Once at $1000^{\circ} \mathrm{C}$, they were held there for 400 hours. The temperature and various parameters of the FBG's performance were recorded throughout the experiment.

\section{A. Long Duration Thermal Evaluation of FBGs Observations}

As in the $750^{\circ} \mathrm{C}$ and $1000^{\circ} \mathrm{C}$ thermal cycling, all three FBGs exhibited similar behavior. A shift of approximately $1.5 \mathrm{~nm}$ per $100^{\circ} \mathrm{C}$ in the Bragg wavelength versus temperature was seen, slightly more than with

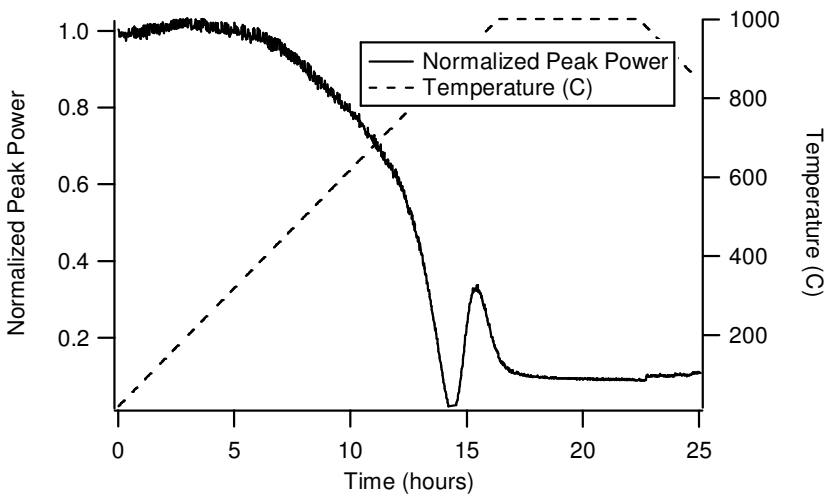

Fig. 8. A close-up of the peak reflected power shown in Fig. 5. The degradation of the original gratings and formation of the O-CCG are easily seen. The solid line is the normalized reflected power and the dashed line is the grating temperature.

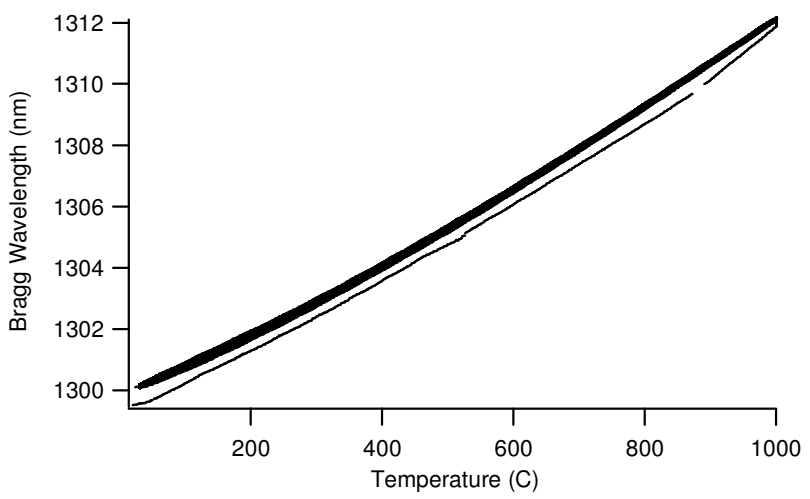

Fig. 7. Typical Bragg wavelength versus temperature response of an $\mathrm{FBG}$ during $1000^{\circ} \mathrm{C}$ thermal cycling. The plot shows two distinct lines. The lower line is the thermal response of the FBG during the initial heating to $1000^{\circ} \mathrm{C}$. The upper, broader line is the response of the FBG over the remainder of the thermal cycling. The gap in the plot is when the original FBG had dissipated and the formation of the O-CCG.

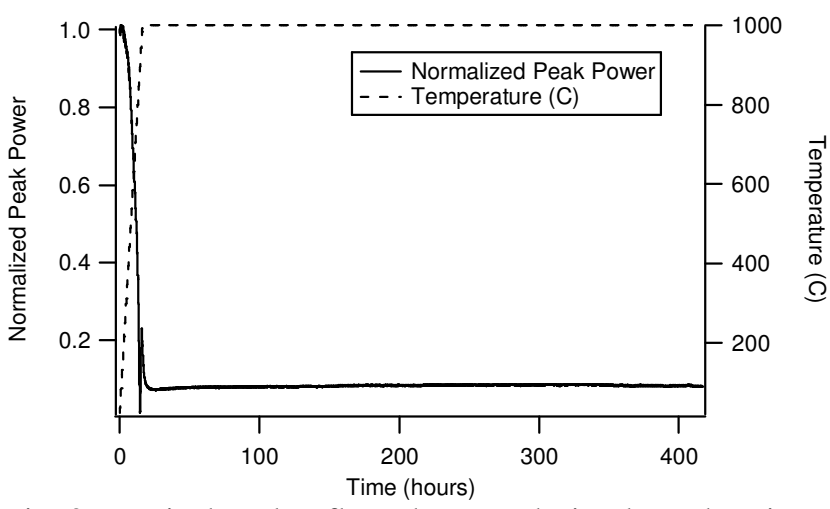

Fig. 9. Typical peak reflected power during long duration $1000^{\circ} \mathrm{C}$ evaluation. After the dissipation of the initial grating the power response from the reformed CCG is very stable, varying less than $1 \%$ over the remainder of the experiment. 
the $1300 \mathrm{~nm}$ gratings used in the cycling experiments. As in the thermal cycling experiments, the temperature versus wavelength response was fairly linear however a $2^{\text {nd }}$ order polynomial is a better fit. The initial FBG dissipated at average temperature of $882^{\circ} \mathrm{C}, 14.3$ hours into the test as seen in Fig. 9 and Fig. 11. This was about the same time to dissipation and temperature as seen in the $1000^{\circ} \mathrm{C}$ thermal cycling experiment using 1300nm FBGs.

As with the 1300nm FBGs, O-CCGs formed in the place on the original gratings. The new O-CCGs appeared at an average temperature of $913^{\circ} \mathrm{C}$ and after 14.8 hours of testing as seen in Fig. 11. The O-CCGs took 0.5 hours on average to form, an average of 0.3 hours longer to form than the 1300nm O-CCGs did during the $1000^{\circ} \mathrm{C}$ thermal cycling experiment.

Similar to the $1300 \mathrm{~nm}$ O-CCGs in the $1000^{\circ} \mathrm{C}$ thermal cycling experiment, the Bragg wavelength of O-CCG exhibited a logarithmically shaped drift while at $1000^{\circ} \mathrm{C}$, rising $0.48 \mathrm{~nm}$ on average in the first 125 hours, then appearing to level off. This initial shift was almost twice the $0.28 \mathrm{~nm}$ drift seen in the $1300 \mathrm{~nm}$ gratings in the $1000^{\circ} \mathrm{C}$ thermal cycling experiment. After the quick rise in the first 125 hours of the experiment, the Bragg wavelength appeared to stabilize, however a slow downward, approximately linear, drift began that continued for the remaining 270 hours of the experiment. During this linear drift, the Bragg wavelength shifted $0.19 \mathrm{~nm}$ on average down from its maximum. The complete response of the Bragg wavelength can be seen in Fig. 12.

The response of the reflected peak power was similar to that seen during $1000^{\circ} \mathrm{C}$ thermal cycling. The decay of the original grating was exponential then exhibited a slightly underdamped type of response with the formation of the new O-CCG. This can be seen in Fig. 11. After the formation of the O-CCG, the peak reflected power from the new grating rose to about $20 \%$ of the original power response then began to decrease. About 5 hours after the formation of the $\mathrm{O}$ CCG the signal stabilized to about $7 \%$ of the original grating. The peak power response would remain stable throughout the remainder of the experiment, varying by no more than a percent for any of the three gratings evaluated.

After an annealing time of 25 hours at $1000^{\circ} \mathrm{C}$, the Bragg wavelength of the O-CCGs proves to be an accurate representation of its temperature. With a drift in the Bragg wavelength of the O-CCGs of no more than $0.19 \mathrm{~nm}$ at $1000^{\circ} \mathrm{C}$ after 25 hours of annealing at $1000^{\circ} \mathrm{C}$, the Bragg wavelength is an indicator of temperature to within $3 \%$ full scale of that measured by the reference s-type thermocouple. A complete summary of the long duration testing can be seen in Table 1 .

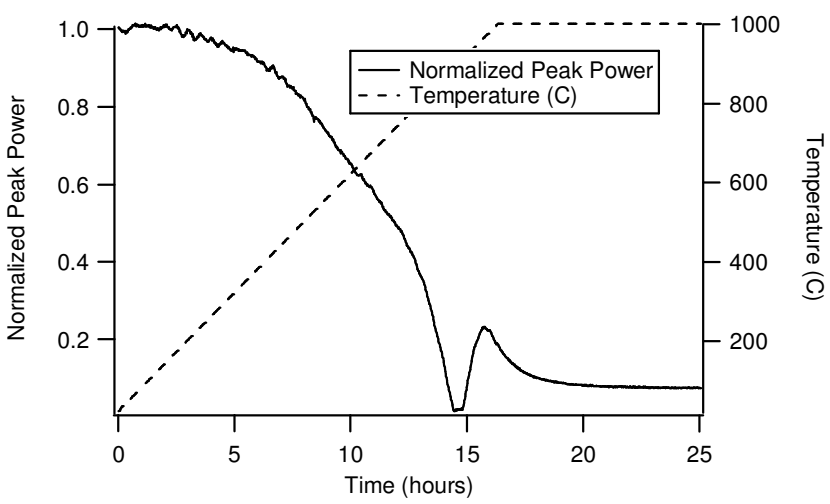

Fig. 11. A close up of the peak reflected power shown in Fig. 9. The degradation of the original gratings and formation of the O-CCG are easily seen. The solid line is the normalized reflected power and the dashed line is the grating temperature.

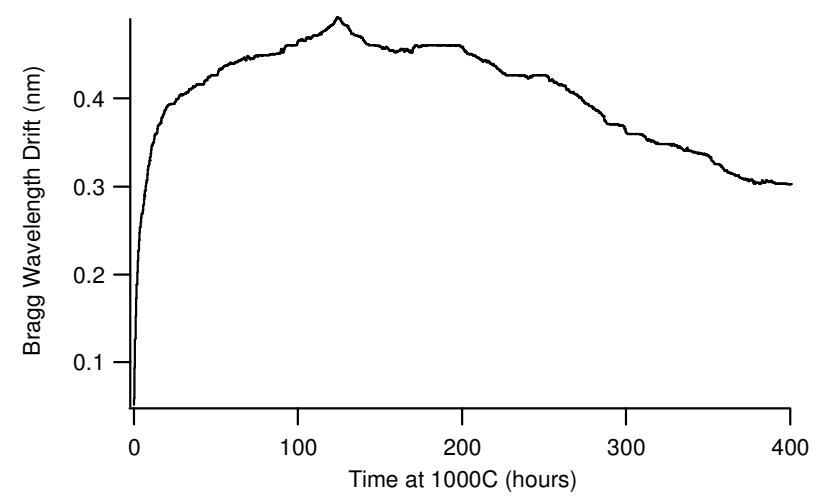

Fig. 12. Typical Bragg wavelength drift while at $1000^{\circ} \mathrm{C}$ during long duration testing. The relatively quick rise then gradual decrease in the peak wavelength was typical.

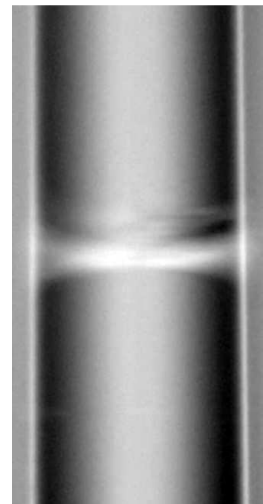

(a)

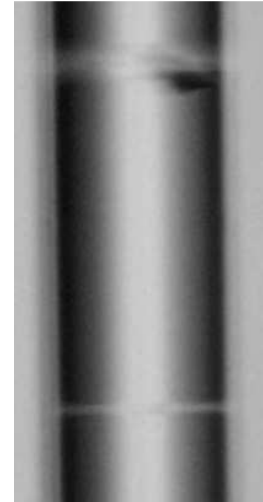

(b)
Fig. 10. Microscopic images of cracks formed in optical fiber during thermal cycling. Both fiber (a) and (b) are 9/125 fiber and are typical of the fiber used throughout the thermal evaluation process. Fibers are shown after the polyimide coating has burned off. Only the cladding is visible in the images. 


\section{MECHANICAL PROPERTIES OF THERMALLY CYCLED FBGS}

The shift of the Bragg wavelength in the last two experiments presented in this paper exhibited a shift that was not initially explainable. To try and shed some light on this unusual behavior a closer examination of the fiber's material properties was undertaken. Work by Rose et al [7] had discussed the devitrification and resulting transmittance loss of optical fibers that were heated to temperatures as low as $850^{\circ} \mathrm{C}$. Samples of our cycled fibers were examined for signs of devitrification but none were visible. However, during the examination of the fibers for signs of crystallization, small cracks were seen in the cladding of the fiber as seen in Fig. 10. (a) and (b). There were no cracks seen in the core.

\section{A. Acoustic Emissions Analysis}

To further investigate the cracking seen in the fibers from the thermal evaluation experiments, samples of the similar fibers without a grating were thermally evaluated while monitoring the fiber for acoustic emissions. An acoustic emission from a fiber is equated to a crack forming somewhere along its length. The experimental setup used is shown in Fig. 13.

\section{B. Acoustic Emissions Analysis Observations}

The results of the acoustic emissions evaluation can be seen in Fig. 14. The solid line indicates the temperature of the gratings and the line with the circles indicates the acoustic emissions count, or cracking. One immediately notices that the shape of the acoustic emissions curve resembles that of the Bragg wavelength drift in Fig. 6 and Fig. 12. The cracking events seemed to occur frequently through the beginning of the experiment but then tapered off. Although not easily seen in Fig. 14, the cracking events seem to occur most frequently during the cooling process. Upon inspection of the fiber the cracks seemed to be visible only in the cladding. No cracks were noted in the fiber core.

\section{Acoustic Emissions Phenomena Theories}

As noted in the previous section the acoustic emissions seem to take on a similar shape to that of the peak wavelength drift. While there is only a circumstantial relationship between the cracking events and the drift of the Bragg wavelength, it seems plausible that the drift seen in the $1000^{\circ} \mathrm{C}$ experiments could be caused by cracking and an associated expansion of the fiber core due to the cracking of the cladding. However, this theory does not explain the reversal of the Bragg wavelength drift seen in the long duration $1000^{\circ} \mathrm{C}$ experiment. Further investigation is needed to confirm a relationship between the cracking events and the drift of the Bragg wavelength.

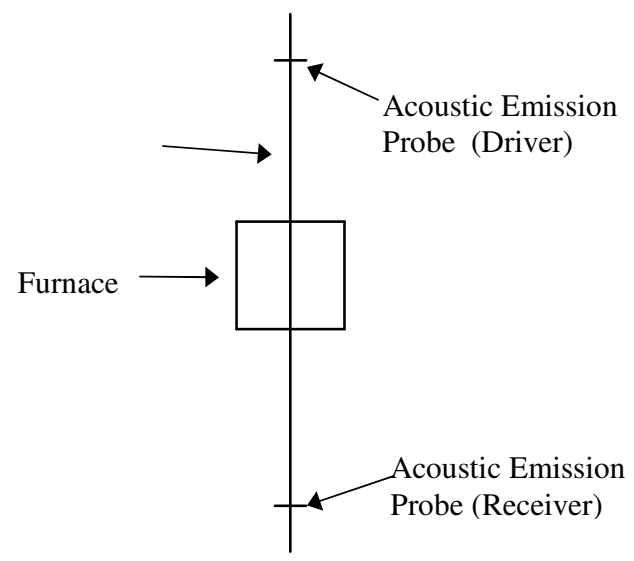

Fig. 13. Experimental set-up for monitoring of acoustic emissions of an optical fiber during thermal cycling.

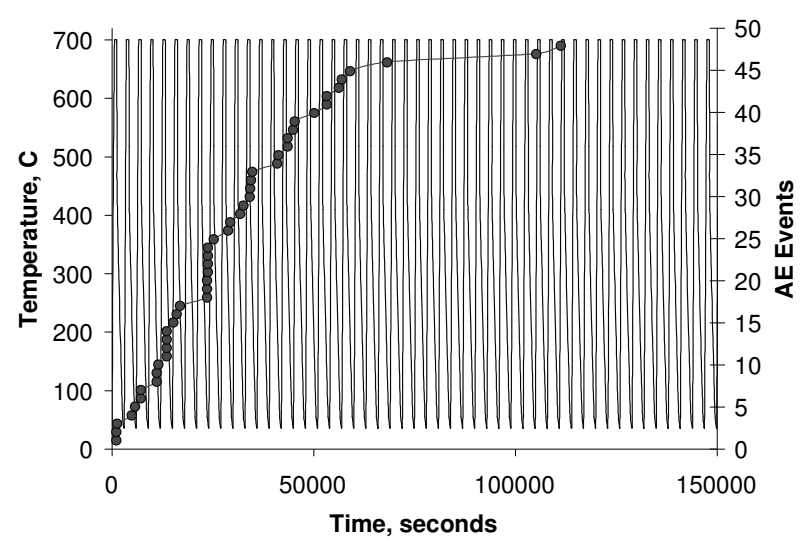

Fig. 14. Acoustic emissions in an optical fiber over a series of thermal cycles. The solid line is the temperature of the cycling while the plot with the circles indicates an acoustic emission count. The acoustics emissions equate to a crack forming somewhere along the length of the fiber. 
Table 1. Summary of the performance of FBGs during thermal evaluation.

\begin{tabular}{|c|c|c|c|c|}
\hline & \multicolumn{3}{|c|}{$\begin{array}{l}\text { 1300nm } \\
\text { Polyimide } \\
\text { Coated }\end{array}$} & \multirow{2}{*}{$\begin{array}{c}1550 \mathrm{~nm} \\
\text { Polyimide } \\
\text { Coated } \\
1000^{\circ} \mathrm{CHold}\end{array}$} \\
\hline & \multicolumn{2}{|c|}{$750^{\circ} \mathrm{C} \mathrm{Cycling}$} & $\begin{array}{l}1000^{\circ} \mathrm{C} \\
\text { Cycling }\end{array}$ & \\
\hline Time to initial dissipation of $F B G$ & $\begin{array}{c}\text { Total time: } \\
\text { 90.2-93.9 HR } \\
\text { Avg.: } 92.1 \mathrm{HR}\end{array}$ & $\begin{array}{l}\text { Time at } 750^{\circ} \mathrm{C}: \\
12.6-16.3 \mathrm{HR} \\
\text { Avg.: } 14.5 \mathrm{HR}\end{array}$ & $\begin{array}{c}\text { 14.2-14.3 HR } \\
\text { Avg.: } 14.3 \mathrm{HR} \\
@ \\
855-878^{\circ} \mathrm{C} \\
\text { Avg.: } 870^{\circ} \mathrm{C}\end{array}$ & $\begin{array}{c}\text { 14.2-14.4 HR } \\
\text { Avg.: } 14.3 \mathrm{HR} \\
@ \\
875-886^{\circ} \mathrm{C} \\
\text { Avg.: } 882^{\circ} \mathrm{C}\end{array}$ \\
\hline Time to appearance of $O-C C G$ & $\begin{array}{l}\text { Total time: } \\
\text { 130.3-136.1 HR } \\
\text { Avg.: } 132.1 \mathrm{HR}\end{array}$ & $\begin{array}{l}\text { Time at } 750^{\circ} \mathrm{C}: \\
\text { 20.0-24.0 HR } \\
\text { Avg.: } 21.3 \mathrm{HR}\end{array}$ & $\begin{array}{c}\text { 14.3-14.5 HR } \\
\text { Avg.: } 14.5 \mathrm{HR} \\
@ \\
880-892^{\circ} \mathrm{C} \\
\text { Avg.: } 888^{\circ} \mathrm{C}\end{array}$ & $\begin{array}{c}\text { 14.8-14.9 HR } \\
\text { Avg.: } 14.8 \mathrm{HR} \\
@ \\
911-915^{\circ} \mathrm{C} \\
\text { Avg.: } 913^{\circ} \mathrm{C}\end{array}$ \\
\hline Formation time of $O-C C G^{*}$ & $\begin{array}{r}37-45 \\
\text { Avg.: } 4\end{array}$ & $\begin{array}{l}9 \mathrm{HR} \\
0.0 \mathrm{HR}\end{array}$ & $\begin{array}{c}\text { 0.1-0.3 HR } \\
\text { Avg.: } 0.2 \mathrm{HR}\end{array}$ & $\begin{array}{c}\text { 0.4-0.6 HR } \\
\text { Avg.: } 0.5 \mathrm{HR}\end{array}$ \\
\hline $\begin{array}{l}\text { Standard deviation of Bragg wavelength } \\
\text { at maximum temperature before } \\
\text { formation of } O-C C G^{\dagger, t}\end{array}$ & $\begin{array}{l}0.02-( \\
\text { Avg.: }\end{array}$ & $\begin{array}{l}.04 \mathrm{~nm} \\
.03 \mathrm{~nm}\end{array}$ & & \\
\hline $\begin{array}{l}\text { Maximum Bragg wavelength drift at } \\
\text { maximum temperature before formation } \\
\text { of } O-C C G^{\ddagger}, s \S\end{array}$ & $\begin{array}{l}0.07-( \\
\text { Avg.: }\end{array}$ & $\begin{array}{l}13 \mathrm{~nm} \\
.10 \mathrm{~nm}\end{array}$ & & \\
\hline $\begin{array}{l}\text { Standard deviation of Bragg wavelength } \\
\text { at maximum temperature after } \\
\text { formation of } O-C C G^{\sharp t, ~}\end{array}$ & $\begin{array}{l}0.01-( \\
\text { Avg.: }\end{array}$ & $.02 \mathrm{~nm}$ & $\begin{array}{l}0.03-0.06 \mathrm{~nm} \\
\text { Avg.: } 0.04 \mathrm{~nm}\end{array}$ & $\begin{array}{l}0.05-0.09 \mathrm{~nm} \\
\text { Avg.: } 0.07 \mathrm{~nm}\end{array}$ \\
\hline $\begin{array}{l}\text { Maximum Bragg wavelength drift at } \\
\text { maximum temperature after formation } \\
\text { of } O-C C G^{\text {t:**** }}\end{array}$ & $\begin{array}{l}0.05-( \\
\text { Avg.: }\end{array}$ & $\begin{array}{l}.09 \mathrm{~nm} \\
.07 \mathrm{~nm}\end{array}$ & $\begin{array}{l}0.23-0.34 \mathrm{~nm} \\
\text { Avg.: } 0.28 \mathrm{~nm}\end{array}$ & $\begin{array}{l}0.45-0.52 \mathrm{~nm} \\
\text { Avg.: } 0.48 \mathrm{~nm}\end{array}$ \\
\hline Total time at maximum temperature ${ }^{* * *}$ & $66 \mathrm{HR}$, & 1 cycles & $\begin{array}{l}96 \mathrm{HR}, 16 \\
\text { cycles }\end{array}$ & $400 \mathrm{HR}$ \\
\hline $\begin{array}{l}\text { Final peak reflected power level as } \\
\text { percent of original power level }\end{array}$ & $\begin{array}{l}11.9 \% \\
\text { Avg.: }\end{array}$ & $\begin{array}{l}15.8 \% \\
13.4 \%\end{array}$ & $\begin{array}{l}9.3 \%-17.8 \% \\
\text { Avg.: } 11.8 \%\end{array}$ & $\begin{array}{l}\text { 6.1\%-8.4\% } \\
\text { Avg.: } 7.5 \%\end{array}$ \\
\hline
\end{tabular}

\footnotetext{
${ }^{*}$ The formation of the O-CCGs occurred over two cycles during the $750^{\circ} \mathrm{C}$ evaluation. The time shown is the total experiment time for their formation.

${ }^{\dagger}$ For $750^{\circ} \mathrm{C}$ testing the statistic shown is for Bragg wavelength at $750^{\circ} \mathrm{C}$. For $1000^{\circ} \mathrm{C}$ testing the statistic shown is for Bragg wavelength at $1000^{\circ} \mathrm{C}$.

${ }^{7}$ For the $1000^{\circ} \mathrm{C}$ cycling, the $\mathrm{O}$-CCGs formed before reaching $1000^{\circ} \mathrm{C}$, thus there are no statistics on the performance of the gratings before the $\mathrm{O}-\mathrm{CCG}$ formed.

${ }^{\S}$ For the $1000^{\circ} \mathrm{C}$ cycling three gratings were cycled 16 times. The fourth grating was subjected to 7 cycles then evaluated for damage to the fiber.
} 


\section{CONCLUSION}

In conclusion, this work has demonstrated the long term survivability of commercially available oxygenchemical composition gratings formed from fiber Bragg Gratings at temperatures up to $1000^{\circ} \mathrm{C}$ through many thermal cycles and also for continuous use at temperature up to $1000^{\circ} \mathrm{C}$. For use up to $750^{\circ} \mathrm{C}$ it has been shown that, after the formation of an O-CCG, peak wavelength response is stable to within a few hundredths of a nanometer and could be used to measure temperature to within the accuracy of the reference measurement. This work has demonstrated that at temperatures up to $1000^{\circ} \mathrm{C}$ the stability of O-CCGs would allow temperature measurements to be made within $3 \%$ of the reference s-type thermocouple. This work has also demonstrated the long term survivability of O-CCGs formed in germanium doped silica fibers through over 400 hours of thermal cycling to $750^{\circ} \mathrm{C}$ and 700 hours of thermal cycling to $1000^{\circ} \mathrm{C}$. The accuracy and stability of O-CCGs for use as temperature sensors for temperatures up to $1000^{\circ} \mathrm{C}$ has been demonstrated.

Throughout this work many similarities to the work of Fokine were observed including the formation O-CCGs [8], similar ratios of decay rate to heat rate in formation of O-CCGs [4], and similar gratings decay behavior [4, 5]. However we saw a trend of shifting to longer wavelengths at high temperatures whereas he indicated a shift to shorter wavelength [2].

\section{REFERENCES}

1. Grobnic, D., Smelser, C., Mihailov, S., Walker, R., "Isothermal Behavior of Fiber Bragg Gratings Made with Ultrafast Radiation at Temperatures Above $1000^{\circ}$ C, " ECOC 2004: 30th European Conference on Optical Communication, Stockholm, Sweden, Sept. 5-9, 2004, Vol.2, Tu1.3.5 (2 p.).

2. Pal, S., Mandal, J., Sun, T., Grattan, K., Fokine, M., Carlson, F., Fonjallaz, P., Wade, S., Collins, S., "Characteristics of potential fibre Bragg grating sensor-based devices at elevated temperatures," Meas. Sci. Technol., Vol. 14, pp. 1131-1136, 2003.

3. Canning, J., Sommer, K., Englund, M., "Fibre gratings for high temperature sensor applications," Meas. Sci. Technol., Vol. 12, pp. 824-828, 2001.

4. Fokine, M., "Thermal Stability of chemical composition gratings in fluorine-geranium-doped silica fibers," Opt. Lett., Vol. 27, pp. 1016-1018, 2002.

5. Fokine, M., "Formation of thermally stable chemical composition gratings in optical fibers," J. Opt. Soc. Am B, Vol. 19, pp. 1759-1765, 2002.

6. Malo, B., Bilodeau, F., Private Communications.

7. Rose, A., "Devitrification in Annealed Optical Fiber," J. Lightwave Technol., Vol. 15, pp. 808-814, 1997.

8. Fokine, M., "Thermal stability of oxygen-modulated chemical composition gratings in standard telecommunication fiber," Opt. Lett., Vol. 29, pp. 1185-1187, 2004.

9. Brambilla, G., "High-temperature fibre Bragg grating thermometer," Elec. Lett., Vol. 38, pp. 954-956, 2002. 
Public reporting burden for this collection of information is estimated to average 1 hour per response, including the time for reviewing instructions, searching existing data sources, gathering and maintaining the data needed, and completing and reviewing the collection of information. Send comments regarding this burden estimate or any other aspect of this collection of information, including suggestions for reducing this burden, to Washington Headquarters Services, Directorate for Information Operations and Reports, 1215 Jefferson Davis Highway, Suite 1204, Arlington, VA 22202-4302, and to the Office of Management and Budget, Paperwork Reduction Project (0704-0188), Washington, DC 20503.

\begin{tabular}{|l|l|l}
\hline 1. AGENCY USE ONLY (Leave blank) & $\begin{array}{c}\text { 2. REPORT DATE } \\
\text { March } 2005\end{array}$ & $\begin{array}{r}\text { 3. REPORT TYPE AND DATES COVERED } \\
\text { Technical Memorandum }\end{array}$ \\
\hline
\end{tabular}

\section{TITLE AND SUBTITLE} 5. FUNDING NUMBERS

Thermal Evaluation of Fiber Bragg Gratings at Extreme Temperatures

6. AUTHOR(S)

WBS-22-066-30-03

Jeffrey Juergens, Grigory Adamovsky, Ramakrishna Bhatt, Gregory Morscher, and Bertram Floyd

\section{PERFORMING ORGANIZATION NAME(S) AND ADDRESS(ES)}

National Aeronautics and Space Administration

John H. Glenn Research Center at Lewis Field

Cleveland, Ohio 44135-3191

9. SPONSORING/MONITORING AGENCY NAME(S) AND ADDRESS(ES)

National Aeronautics and Space Administration

Washington, DC 20546-0001

8. PERFORMING ORGANIZATION REPORT NUMBER

E-15005

10. SPONSORING/MONITORING AGENCY REPORT NUMBER NASA TM-2005-213560 AIAA-2005-1214

\section{SUPPLEMENTARY NOTES}

Prepared for the 43rd Aerospace Sciences Meeting and Exhibit sponsored by the American Institute of Aeronautics and Astronautics, Reno, Nevada, January 10-13, 2005. Jeffrey Juergens and Grigory Adamovsky, NASA Glenn Research Center; Ramakrishna Bhatt, U.S. Army Research Laboratory, NASA Glenn Research Center; Gregory Morscher, Ohio Aerospace Institute, 22800 Cedar Point Road, Brook Park, Ohio 44142; and Bertram Floyd, Akima Corporation, 22021 Brookpark Road, Fairview Park, Ohio 44126. Responsible person, Jeffrey Juergens, organization code DDI, 216-433-5460.

12a. DISTRIBUTION/AVAILABILITY STATEMENT 12b. DISTRIBUTION CODE

Unclassified - Unlimited

Subject Category: 35 and 74

Available electronically at http://gltrs.grc.nasa.gov

This publication is available from the NASA Center for AeroSpace Information, 301-621-0390.

\section{ABSTRACT (Maximum 200 words)}

The development of integrated fiber optic sensors for use in aerospace health monitoring systems demands that the sensors be able to perform in extreme environments. In order to use fiber optic sensors effectively in an extreme environment one must have a thorough understanding of the sensor's capabilities, limitations, and performance under extreme environmental conditions. This paper reports on our current sensor evaluation examining the performance of freestanding fiber Bragg gratings (FBG) at extreme temperatures. While the ability of FBGs to survive at extreme temperatures has been established, their performance and long term survivability is not well documented. At extreme temperatures the grating structure would be expected to dissipate, degrading the sensors performance and eventually ceasing to return a detectable signal. The fiber jacket will dissipate leaving a brittle, unprotected fiber. For FBGs to be used in aerospace systems their performance and limitations need to be thoroughly understood at extreme temperatures. As the limits of the FBGs performance are pushed the long term survivability and performance of the sensor comes into question. We will not only examine the ability of FBGs to survive extreme temperatures but also look at their performance during many thermal cycles. This paper reports on test results of the performance of thermal cycling commercially available FBGs, at temperatures up to $1000{ }^{\circ} \mathrm{C}$, seen in aerospace applications. Additionally this paper will report on the performance of commercially available FBGs held at $1000{ }^{\circ} \mathrm{C}$ for hundreds of hours. Throughout the evaluation process, various parameters of the FBGs performance were monitored and recorded. Several test samples were subjected to identical test conditions to allow for statistical analysis of the data. Test procedures, calibrations, referencing techniques, performance data, and interpretations and explanations of results are presented in the paper along with directions for future research.

\section{SUBJECT TERMS}

Fiber optics; Bragg gratings; Optical fibers

\begin{tabular}{|c|c|c|c|}
\hline $\begin{array}{c}\text { 17. SECURITY CLASSIFICATION } \\
\text { OF REPORT } \\
\text { Unclassified }\end{array}$ & $\begin{array}{c}\text { 18. SECURITY CLASSIFICATION } \\
\text { OF THIS PAGE } \\
\text { Unclassified }\end{array}$ & $\begin{array}{c}\text { 19. SECURITY CLASSIFICATION } \\
\text { OF ABSTRACT } \\
\text { Unclassified }\end{array}$ \\
\hline
\end{tabular}



